\title{
INTRA VITAM STAINING WITH METHYLENE BLUE
}

\author{
J. GORDON WILSON \\ Northwestern University Medical School
}

The purpose of this paper is not to give a detailed account of the various modifications of this important technic, it is rather to state clearly the particular methods which I have found most suitable and to point out the pitfalls a beginner has to avoid. That this technic is so little used and that it has beenso unsuccessful in the hands of many seems sufficient justification for the account.

In 1885 Ehrlich drew attention to the fact that if a solution of methylene blue in physiological salt solution be injected into the blood vessels of a living animal the nerve cells and their processes showed an affinity for this dye. The tissue when removed and examined under the microscope usually shows no nerves, but on exposure to the air these gradually appear. The reaction depends on the fact that the coloring property of a dye is due to the presence of a group of atoms with a marked affinity for hydrogen. The introduction of hydrogen into this unsaturated radical results in a loss of color; $;$ but this leuco-combination can be easily oxidized by the air to the original color. One may suppose that the "vital color," methylene blue, circulating in the blood is selected by certain cells by an extractive process, the "ausschüttelungs process," ${ }_{2}$ involving a reduction to the leucobase by the addition of hydrogen as a result of functional activity or post-mortem change. Exposure to the air oxidizes this to the original dye. It is, however,

1 Nietzki, R.-Chemie der organischen Farbstoffe, Berlin, 1901, pp. 2 and 3.

2 Ehrlich, Paul-Collected Studies on Immunity, New York, 1906. Article 34. The relation existing between chemical constitution, distribution and pharmacological action. 
not sufficiently anchored in the cell, but can be fixed there by the action of certain acids which precipitate it in an insoluble form.

The importance of this "vital staining" reaction was quickly recognized and it is now a procedure which has found extensive application in the histology of the nervous system. Failure to obtain this selective action is not uncommon and arises from many causes, for instance, the difficulty of obtaining fresh tissue, the particular part examined, the fixation and subsequent treatment requisite to insure dehydration. The adequate saturation of the tissue with the dye, its reduction in the nerve and its subsequent oxidation are easily accomplished. In regard to the freshness of the tissue, the sooner after death it is obtained, the better the result. Animal tissue can usually be obtained immediately on death or very soon after. In man it is remarkable how many hours post mortem the nerves and their endings react to the dye; in some cases I have obtained satisfactory results six to eight hours after death, when the body has been kept in a cold chamber.

In some tissues the nerves react to the dye more readily than in others. Thus they are easily obtained in muscle, and here the motor endings appear more readily than the sensory endings or the vaso-motor nerves. Endings are easily demonstrated in the tongue and epiglottis but with more difficulty in the lung and in the liver. While this can be explained to some extent by the condition of the blood supply and the variety of nerve, it appears to me that some substance is often present around the terminal ending interfering with the reaction. The accessibility of oxygen to the reduced dye has always to be considered; thus the nerves of the skin stain with difficulty when the epithelial surface is exposed to the air; but if cut transversely and so exposed, the blue quickly appears.

The part of the technic in which one meets with the greatest difficulty is the process of dehydrating. The fixed dye is extremely soluble in all grades of alcohol excepting absolute. As the removal of a minute amount of the dye from the fine nerve ending is detrimental to a satisfactory result, it is to this part of the procedure that most care has to be directed.

The kind of methylene blue used is of importance. There are 
many varieties of this dye; as it comes into commerce it is a zinc chloride double salt. For vital staining this dye is useless. A zinc-free salt is requisite; of these the one that answers best is the methylene blue "nach Ehrlich" prepared by Dr. Grübler of Leipsic. Another which gives fairly good results is the medicinally pure methylene blue.

Absolute cleanliness of the vessels used cannot be too strongly insisted on. The slides and instruments should be kept in physiological salt solution.

To get the dye to the nerve, there are three methods which I use, varying according to the animal or the part to be examined: I. The injection method-Ehrlich's method. II. The placing of a thin section on a slide and keeping it covered with the dyeDogiel's method. III. The immersing of the tissue in a weak solution of the blue till it becomes permeated with the dye; then exposure to the air.

I. For the injection method it is-generally recommended to use a $\frac{1}{4}-\frac{1}{6} \%$ solution of methylene blue. This I consider too strong and too apt to color other tissues which will later be referred to, and so to obscure the nerves and their endings. I therefore use a solution never stronger than ${ }_{20}^{1} \%$. A stock solution of methylene blue $0.5 \%$ in distilled water is made, and when ready to inject the following is prepared:

$$
\begin{aligned}
& \text { Methylene blue }(0.5 \% \text { sol. })-10 \mathrm{cc} \text {. } \\
& \text { Salt solution }(0.75 \% \text { sol. })-90 \mathrm{cc} .
\end{aligned}
$$

Even this will often color other tissues too much and then the strength must be reduced. Before injecting, this solution is heated to slightly over $37^{\circ} \mathrm{C}$. In small animals, e.g., the white rat, it is most suitably injected into the aorta or heart; in large animals the vessel selected should be near the part to be investigated; thus for endings in the muscle of the eye, or of the tongue in a dog, the injection may be made into the common carotid.

Before injecting, the animal is given an anæsthetic and bled. A glass canula may be inserted into the artery and the fluid 
injected from a flask; or a syringe with a blunt needle may be used. I prefer the latter; with a little practice one can so arrange that the syringe can be withdrawn from the needle fixed in the artery, refilled and applied to the needle without air getting into the vessels. I do not now wash out with salt solution. While recognizing that it is absolutely essential for satisfactory staining to have the capillaries and veins thoroughly empty of blood, I find that this is accomplished most satisfactorily and with less damage to the tissue by bleeding thoroughly and then during the injecting to open a neighboring vein and allow the methylene blue to flow through this exit till the solution escapes uncolored by blood and with its distinctive blue. Then I clamp the vein and fill well all the blood vessels. The test by which this can be gauged is that the tissue to be examined be distinctly blue; or if the tissue be too deep to be seen without dissection, for instance in the $\mathrm{m}$. tensor tympani, that the surrounding parts are well colored. To get this result it may be necessary to clamp all the vessels connected with the part, thus in the head, all the vessels of the head and neck coming from the arch of the aorta as well as those entering the superior vena cava.

The injected part is now left untouched for 5 to 10 minutes; then the part to be examined is exposed. Free entrance of air to the tissues is essential; at times one exposes the part to be examined for a few minutes before removing pieces of suitable size for microscopic examination. This removal may be done with a sharp broad knife, scissors, or a Valentine knife. The section is placed on a clean glass slide moistened with salt solution and examined under the low power. It may be, that already nerves are to be seen; if not, the slide is laid in a Petri dish and placed in the thermostat at $37^{\circ} \mathrm{C}$. From time to time the section is examined under the low power of the microscope, say every five minutes, till the nerves are sufficiently clearly seen, care being taken in the meantime that the tissue is kept moist by the application of the salt solution. The recognition of how soon the tissue may be regarded as satisfactorily colored is a matter of experience, but in each piece the nerves will be seen in various stages of coloration. As a rule the tissue should be fixed too soon rather than too late. If kept too 
long the blue diffuses out and a blurred appearance results. If the nerves do not appear within one hour it may be regarded as useless to expect them. It is interesting here to note that the nerves do not invariably appear blue - they occasionally are of a violet or reddish purple. This opens an interesting field for investigation as to what has caused this transformation.

In frogs the injection can be best done from the heart or vena abdominalis. In cold-blooded animals the solution is not warmed, nor is the tissue placed in the thermostat.

As a modification of this, one may inject the solution directly into the part. This is veryuseful in man, injecting subcutaneously to examine the skin for nerve endings, injecting into the museles for motor or sensory endings. It is an easy method of preparing class preparations, for example, to demonstrate motor and sensory endings as well as vaso-motor nerves in the $\mathrm{m}$. sartorius of the frog. When so used I prefer the solutions $\frac{1}{2}$ or $\frac{1}{4}$ of the above strength. When the tissue is well colored the part is cut out, placed on a slide, examined and fixed in the usual way.

II. In the second method the piece of tissue freed from blood (if necessary by rinsing in saline solution) is cut to a suitable size, placed on a glass slide and its surface moistened with the $\frac{1}{20} \%$ solution of methylene blue at $37^{\circ} \mathrm{C}$. It is then laid in a Petri dish and placed in the thermostat at $37^{\circ} \mathrm{C}$. in the case of warm-blooded animals and at room temperature for cold-blooded animals. It is examined from time to time and kept moist with the solution. To prevent it drying I usually raise the slide slightly above the bottom of the dish and keep a little distilled water or damp cotton wool in the dish. Within a varying time, up to 2 hours; the nerves appear.

III. The method which I have recently used very largely and which has proved more effectual than Method II for human tissue and for the organs of large animals such as the heart of the calf, is immersion of the tissue for a short period in a weak solution and then exposure to the air. The details applied to the heart of a calf are as follows: 
a. With a Valentine knife a section is cut of the part to be examined about $1 \mathrm{~mm}$. thick, the size otherwise being of no moment; some of my sections have been 3 to $4 \mathrm{~cm}$. long and 1 to $1 \frac{1}{2} \mathrm{~cm}$. in breadth.

b. This is immersed in a weak solution of methylene blue at $37^{\circ} \mathrm{C}$. and placed in thermostat for 5 to 10 minutes or till the tissue is well colored blue. For this purpose I use

$$
\begin{aligned}
& \text { Methylene blue }(0.5 \% \text { sol. }) \\
& \text { Salt solution.... }(0.75 \% \text { sol. })
\end{aligned}
$$

Often a much weaker solution answers better.

c. The tissue is now taken out of the solution and placed on a glass slide in a Petri dish, moistened with the blue solution and placed in the thermostat at $37^{\circ} \mathrm{C}$.

d. At a varying time the nerves appear, the interval varying with the time after death at which the tissue has been obtained. They may begin to appear as early as from 10 to 20 minutes or they may not appear for an hour.

The human heart may be treated in exactly the same way. The time at which the nerves appear varies with the time after death, the longer after death the slower the appearance; it also varies with the animal, thus in the sheep and ox they appear more slowly than in the calf. It will be noted that I use the weakest possible solution because since the nerves attract the dye more readily than do the other tissues, a clearer picture can thus be obtained.

\section{FIXATION}

The dye has to be fixed in the nerve, otherwise it quickly disappears. To secure this, one may employ either 1 , the ammonium picrate method of Dogiel, or 2, the ammonium molybdate method of Bethe.

1. In the ammonium picrate method the tissue is placed in a saturated filtered solution of ammonium picrate (Grübler's) in water. Here it is left for from 4 to 24 hours according to its size It is then transferred to a mixture of equal parts of glycerin and 
the above solution in which it clears and in this it is mounted and examined. While there are certain cases in which this method is of great use, for example in the examination of teased preparations, yet for detailed study and accurate results it is inferior to the method of Bethe.

2. For routine work Bethe uses a $5 \%$ solution of ammonium molybdate. At first he recommended various additions to this solution, such as hydrochloric acid (a few drops), peroxide of hydrogen, osmic acid, etc. Experience has shown that these are super- fluous and they are now but little used. I constantly fix with an $8 \%$ solution. The kind of molybdate used is of some importance. The large crystalline variety prepared by Merck or by Kahlbaum is to be preferred. The crystals are added to the distilled water in a flask; the mixture is heated, but not allowed to boil, till the crystals are dissolved. A large amount of the molybdate solution must be used. Before placing the tissue in this fixing agent it is advisable to cool the solution to about $35-40^{\circ} \mathrm{F}$. by placing it in a cold chamber. Into this the tissue is placed and left over night in a cold chamber. It appears to me that the molybdate solution has an oxidizing effect, and so it is preferable to fix the nerves as they are coming out rather than after they have been out for some time. Unless this is done the picture is less sharp, due to the blue being fixed as it is diffusing out from the axis cylinder. The oxidizing effect of the molybdate will also account for the greenish yellow color so often seen, as for example in the muscle cell.

I have used a mixture of osmic acid and ammonium molybdate in order to obtain a combination of the blue axis cylinder with a brown coloration of the medullary sheath. The tissue is placed for 1-2 hours in the following solutions:

Ammonium molybdate $(8 \%$ sol. $) \ldots \ldots \ldots \ldots \ldots \ldots \ldots \ldots \ldots \ldots \ldots \ldots \ldots \ldots \ldots \ldots \ldots \ldots \ldots \ldots \ldots \ldots \ldots \ldots \ldots \ldots$
Osmic acid $\left(\frac{1}{2} \%\right.$ sol. $) \ldots \ldots \ldots \ldots \ldots \ldots$

The amount of osmic acid must be just sufficient to stain the tissue a light brown. After the expiration of this time the tissue is transferred to an $8 \%$ molybdate solution in which it is left over 
night. In using this technic I do not allow the nerves to appear well under the low power because the oxidizing effect of the osmic acid is sufficient to assist in transforming the leucobase.

\section{WASHING.}

The tissue must be washed to remove the molybdate. This may be done in one of two ways:

a. By using several changes of distilled water for 1 to 2 hours. It is a good plan to keep the water cool by having a piece of ice. in it because in all laboratories the water is apt to be warm and the dye dissolves out, in small amount, it is true, but sufficient to spoil the final results.

b. Recently I have washed the tissue in ordinary cold tap water running very slowly, by which the time of washing is very considerably reduced to from $\frac{1}{2}$ to 1 hour. Any means of shortening the time between fixation and embedding is of distinct advantage; the aim should be to get this done in one day.

\section{ALCOHOL TO PARAFFIN.}

The method of passing the tissues through alcohol is of the utmost importance. Alcohol, even 96 per cent, will extract the dye; in absolute alcohol the dye is practically insoluble. I have left well dehydrated tissue over night in absolute alcohol without a trace of the dye showing in the liquid. My mode of procedure is as follows: On removing the tissue from the water the surface water is removed with blotting paper. I do not press the blotting paper on it but simply lay the tissue for a few seconds on the paper. It is now immersed in 96 per cent alcohol and rinsed; then transferred to fresh 96 per cent alcohol for about 5 minutes, again transferred to 96 per centalcohol for 20 minutes and again to 96 per cent alcohol for 1 hour. In all this procedure the alcohol is kept at a temperature of about 40 degrees $F$. in a cold chamber. The number of times this is done depends on the thickness of the tissue and the amount of shrink- 
ing one wants to avoid; thus in some cases I have kept the tissue in 96 per cent alcohol altogether for from 2 to 4 hours.

Now it is transferred to absolute alcohol. It is best to have the first change of absolute in the cold chamber but after this it may be kept at the room temperature. It is well to remember that during the process of dehydration the absolute alcohol becomes diluted and that as the diffusion of alcohol in water is slow, one can then see a ring of color immediately surrounding the tissue. It is advisable to have thin pieces and to hurry the process on to xylol and paraffin, but absolute dehydration is most essential. Xylol is by far the most satisfactory clearing agent; most of my tissues about 1 to $2 \mathrm{~mm}$. thick clear in about $\frac{1}{2}$ hour.

- The tissues may then be mounted in Canada balsam and examined; or they may be passed into paraffin. The partffin used is a matter of choice. Lately I have immersed the tissue in soft paraffin in a vacuum bath for $1 \frac{1}{2}$ to 2 hours; then into hard paraffin for a minute, imbedding in hard paraffin. Once in paraffin the tissue is safe; I have cut paraffin blocks after 4 years and found the tissue in perfect condition.

We can briefly summarize these methods as follows:

I. Injection method.

1. Anæsthetise and bleed animal.

2. Inject into artery $\frac{1}{20}$ per cent methylene blue till part well colored.

3. Cut out part and examine under low power of microscope; if no nerves then

4. Keep moist in thermostat at $37^{\circ} \mathrm{C}$. tillnerves appear $-15 \mathrm{~min}$. to 1 hour.

5. Fix in 8 per cent ammonium molybdate over night.

6. Wash in cold water for $\frac{1}{2}$ to 2 hours.

7. Pass through several changes of 96 per cent alcohol at a low temperature for $\frac{1}{2}$ to $2 \mathrm{hrs}$.

8. Pass through several changes of absolute alcohol for 1 to 2 hours.

9. Clear in xylol.

10. Mount in Canada balsam or embed in paraffin. 
II. Dogiel method.

1. Small pieces of tissue from animal recently killed, free from blood, are placed on slide and moistened with $\frac{1}{2} \sigma$ per cent methylene blue, and kept at temperature of $37^{\circ} \mathrm{C}$. till nerves appear-usually within one hour.

2. Fixation and after treatment as in method I. For modifications for cold blooded animals and for ammonium picrate fixation, see text.

III. Immersion method especially suitable for human tissue and for the tissue of large animals.

1. Immerse as soon after death as possible a thin section of tissue freed from blood in a $\frac{1}{40}$ per cent solution of methylene blue at $37^{\circ} \mathrm{C}$. till permeated by blue, for 5 to 15 minutes.

2. Remove from solution, place on a glass slide and keep moist with the above solution at $37^{\circ} \mathrm{C}$. till nerves appear, $\frac{1}{2}$ to 2 hours varying with time after death.

3. Fixation and after treatment as in Method I.

\section{SOURCES OF ERROR}

In all methylene blue investigations it must never be forgotten that while the dye is neurotropic it is not monotropic, otherwise one may be led to false deductions. In intra vitam staining in addition to nerve tissue there are colored by the dye elastic fibers, pigment and connective tissue cells, fat cells and muscle cells. Fat cells and muscle cells never cause any confusion; but the others require to be constantly kept in mind as a possible source of error. The elastic fibers especially if in single strands may at times look like nerves, but the absence of the typical varicosities and their mode of branching are sufficiently distinctive. This error is likely to occur only to a beginner or in unsatisfactorily stained tissues. The connective tissue cell 
and the pigment cell with their branching processes have not infrequently been mistaken for ganglion cells. This mistake can only occur in smaller cells when the nucleus is either not seen or badly stained. The large ganglion cell with its distinctive nucleus and halo never presents any difficulty. The small pigment cells in which the nucleus has not appeared well, at times may resemble at first glance a ganglion cell; but the processes are different and can never be traced to the same length as in the ganglion cell nor do they branch with the same regularity. A comparison of a doubtful cell with a ganglion cell always will solve the doubt.

To some this account may appear too minute but I have seen so many failures from "slight alterations" or lack of attention to an apparently insignificant point that an excess of detail may well be pardoned. I have added no bibliography since this has been done so amply by Dogiel $^{3}$ in a recent article.

${ }^{3}$ Dogiel, A. S. Methylenblau zur Nervenfärhung. Encyklopädie der Mikroskopischen Technik. Bd. 2, Berlin, 1905. 